\title{
OA07-03. Influence of preexisting vaccinia immunity on a DNA/MVA SIV vaccine, decreased cellular immunity but enhanced control of a pathogenic SIV challenge
}

\author{
S Kannanganat ${ }^{4}$, P Nigam ${ }^{4}$, V Velu ${ }^{4}$, P Earl ${ }^{1}$, L Lai ${ }^{4}$, B Lawson ${ }^{4}$, \\ L Chennareddi ${ }^{4}$, R Wilson' ${ }^{2}$, P Kozlowski ${ }^{2}$, B Moss ${ }^{1}$, H Robinson ${ }^{3}$ and \\ R Amara*4
}

\begin{abstract}
Address: ${ }^{1}$ Laboratory of Viral Diseases, NIH, Bethesda, MD, USA, ${ }^{2}$ Louisiana State University Health Sciences Center, New Orleans, LA, USA, ${ }^{3}$ Geovax Inc., Atlanta, GA, USA and ${ }^{4}$ Microbiology and Immunology, Yerkes National Primate Center of Emory University, Atlanta, GA, USA

* Corresponding author
\end{abstract}

from AIDS Vaccine 2009

Paris, France. 19 - 22 October 2009

Published: 22 October 2009

Retrovirology 2009, 6(Suppl 3):O5I doi:10.1 186/I742-4690-6-S3-O5I

This abstract is available from: http://www.retrovirology.com/content/6/S3/O5I

(c) 2009 Kannanganat et al; licensee BioMed Central Ltd.

\section{Background}

The influence of preexisting immunity to viral vectors is a major issue for the development of viral vectored vaccines. Here we report that for a DNA/MVA vaccine, preexisting immunity to vaccinia virus (Dryvax) decreases cellular immune responses but enhances control of an intrarectal SIV challenge.

\section{Methods}

Three groups of rhesus macaques, eight per group, were studied. The Dryvax-naive and Dryvax-immune groups received the DNA/MVA SIV vaccine (DNA at weeks 0 and 8 , and rMVA at weeks 16 and 24). In addition, the Dryvaximmune group received the Dryvax vaccine 1.5 years prior to the DNA prime. The control group did not receive any vaccine. All macaques were challenged intrarectally with SIV251 at 9 months after the final MVA.

\section{Results}

Following vaccination, the frequency of SIV Gag-specific CD4 and CD8 T cells were 510 fold lower in the Dryvaximmune group than the Dryvax-naive group. Despite their low SIV-specific $\mathrm{T}$ cell responses, the Dryvax-immune macaques exhibited the best control of SIV challenge with viremia 480-fold lower at peak and 40-fold lower at set point than in the unvaccinated control animals $(\mathrm{p}=0.01)$.
The enhanced control in the Dryvax-immune animals was not restricted to Mamu $\mathrm{A}^{*} 01+$ animals and was strongly associated with reduced colorectal virus at 2 weeks post challenge. Factors that correlated with early colorectal viral control included the magnitude of vaccine-elicited CD4 T cells displaying the CCR5 viral co-receptor, which was dampened in the Dryvax-immune animals; the presence of anti-viral mucosal IgA, which was more frequent in the Dryvax-immune animals, and the avidity of the anti-Env Ab response. The frequency of anti-viral CD8 T cells did not correlate with early colorectal viral control.

\section{Conclusion}

These results highlight important roles for vaccine-elicited CCR5+ CD4 T cells in augmenting, and mucosal IgA and high avidity anti-Env IgG in restricting the early replication of a colorectal immunodeficiency virus challenge. 